\title{
Ride-Through Technique for PMSG Wind Turbines using Energy Storage Systems
}

\author{
Thanh Hai Nguyen* and Dong-Choon Lee ${ }^{\dagger}$ \\ ${ }^{\dagger *}$ Dept. of Electrical Engineering, Yeungnam University, Gyeongsan, Korea
}

\begin{abstract}
This paper deals with a ride-through technique for permanent-magnet synchronous generator (PMSG) wind turbine systems using energy storage systems (ESS). A control strategy which consists of current and power control loops for the energy storage systems is proposed. By increasing the generator speed, some portion of the turbine power can be stored in the system inertia. Therefore, the required energy capacity of the ESS can be decreased, which results in a low-cost system. In addition, the power fluctuations due to wind speed variations can be smoothened by controlling the ESS appropriately. The effectiveness of the proposed method is verified not only by the simulation results for a 2[MW] PMSG wind turbine system, but also by the experiment results for a reduced-scale turbine simulator.
\end{abstract}

Key Words: Energy storage system, PMSG, Power smoothening, Ride-through

\section{INTRODUCTION}

Among renewable energy sources, wind energy generation has been noted as the most rapidly growing technology; being one of the most cost-effective and environmental friendly means to generate electricity from renewable sources. The increasing penetration level of wind energy can have a significant impact on the grid, especially under abnormal grid voltage conditions. Thus, wind farms can no longer be considered as a simple energy source. Nowadays, they should provide an operational ability similar to that of conventional power plants. A demanding requirement for wind farms is the fault ride-through capability. According to this demand, the wind turbine is required to survive during grid faults. The ability of a wind turbine to survive for a short duration of voltage dip without tripping is often referred to as the low voltage ridethrough (LVRT) capability of a turbine. An LVRT requirement for wind turbine systems is shown in Fig. 1 [1]. On the other hand, power fluctuation from a turbine due to wind speed variations incurs a deviation of the system frequency from the rated value [2], [3]. As a result, it is necessary to mitigate this power fluctuation for high power quality.

Variable-speed wind turbines using a PMSG equipped with full-scale back-to-back converters are very promising and suitable for application in large wind farms. Due to their

full-scale power converter, they can deliver a larger amount of reactive power to the grid than a DFIG wind turbine under abnormal grid conditions.

In order to achieve LVRT capability for wind turbine

\footnotetext{
Manuscript received Apr. 19, 2010; revised Aug. 25, 2010

$\dagger$ Corresponding Author: dclee@yu.ac.kr

Tel: +82-53-810-2582, Fax: +82-53-810-4767, Yeungnam Univ.

* Dept. of Electrical Engineering, Yeungnam University, Gyeongsan, Korea
}

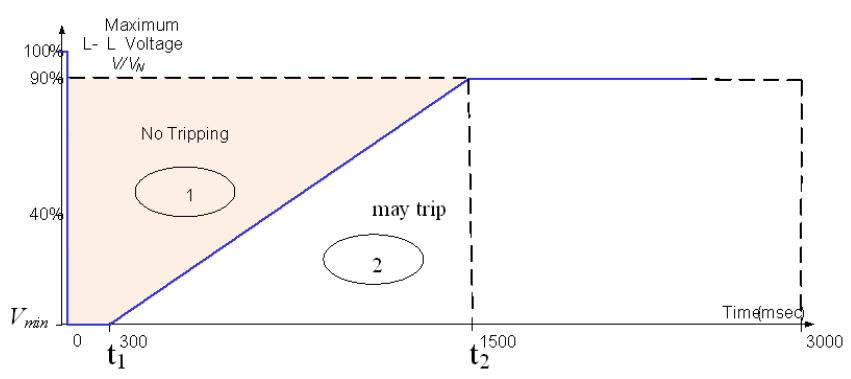

Fig. 1. A grid code.

systems, a braking chopper was proposed in [4]-[6], which is a relatively cheap solution with a simple control. However, it is hard to smoothen the fluctuated power from the turbine, and the generated power is dissipated in the braking resistor.

On the other hand, other methods using an energy storage system have been proposed [4], [7], [8]. These methods are not suitable for LVRT since the energy and power capacity of the ESS should be high enough to absorb the full differential power between the generator and the grid during the voltage sag. However, it can be applied to smoothen power fluctuations [9], [10]. A study using an ESS for both LVRT and power smoothening has been proposed [6], but the control algorithm for the ESS was not shown in detail and the power rating of the ESS was too high.

In order to reduce the minimum energy and power capacity of an ESS so that it can absorb the full differential power under grid voltage dips, the generator speed can be increased to store the kinetic energy in the system inertia. During this operation, the turbine output power extracted from the wind is not maximal since the generator speed is not the optimal value for the MPPT (maximum power point tracking) [11]. 


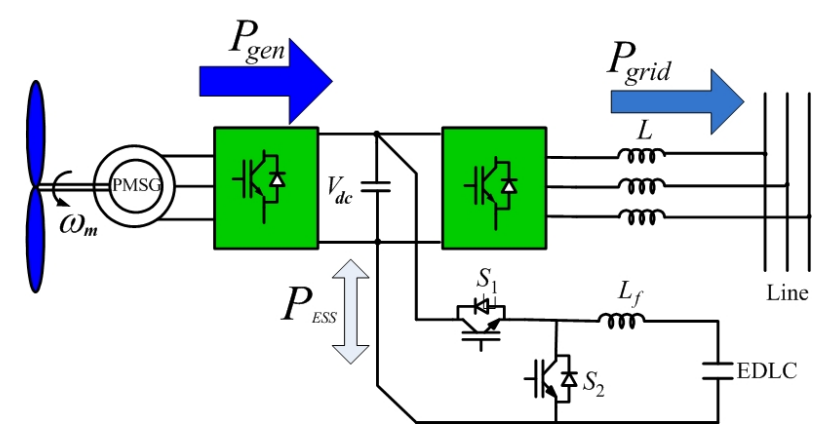

Fig. 2. PMSG wind turbine system with ESS.

In this work, a ride-through technique for PMSG wind turbine systems using an ESS is proposed. By storing the more inertial energy in the rotational body of the system by increasing the generator speed, the energy capacity of the ESS required can be reduced. In addition, an ESS integrated into PMSG wind turbine systems can also be used to improve the generator output power within the capacity of the ESS by charging or discharging the fluctuated component of the power under wind speed variations. The design procedure of the ESS is described in detail. The ESS consists of a DCDC buck/boost converter and an EDLC, which is connected at the DC-link of the back-to-back converters as shown in Fig. 2. A control strategy for the ESS composed of power and current controllers is suggested, resulting in an improvement in the overall performance for both ride-through and power smoothening. The validity of the proposed control algorithm is verified by simulation and experimental results.

\section{Control of Back-to-Back Converters}

A line-side converter (LSC) has a conventional cascaded control structure composed of an inner current control loop and an outer DC-link voltage control [12]-[13]. For vector control of a PMSG, a cascaded control scheme composed of an inner current control loop and an outer speed control loop is employed. In order to obtain maximum torque at a minimum current, the d-axis reference current component is set to zero and then the q-axis current is proportional to the active power, which is determined by the speed controller.

The control block diagram of a PMSG wind turbine is shown in Fig. 3. The MPPT method is applied for turbine power control [8], which gives the speed reference of the PMSG under normal grid conditions. At a grid voltage sag, however, the MPPT control stops in order to reduce the turbine power extracted from wind. During this operation, the speed reference of the system is set higher than in the case of presag, which means that some portion of the turbine power can be stored in the system inertia.

The dynamic equations of the two-mass model of a PMSG wind turbine system without a gearbox, shown in Fig. 4, are expressed as:

$$
\begin{aligned}
& T_{t}-T_{k}=J_{t} \frac{d \omega_{t}}{d t} \\
& T_{k}-T_{g}=J_{g} \frac{d \omega_{g}}{d t}
\end{aligned}
$$

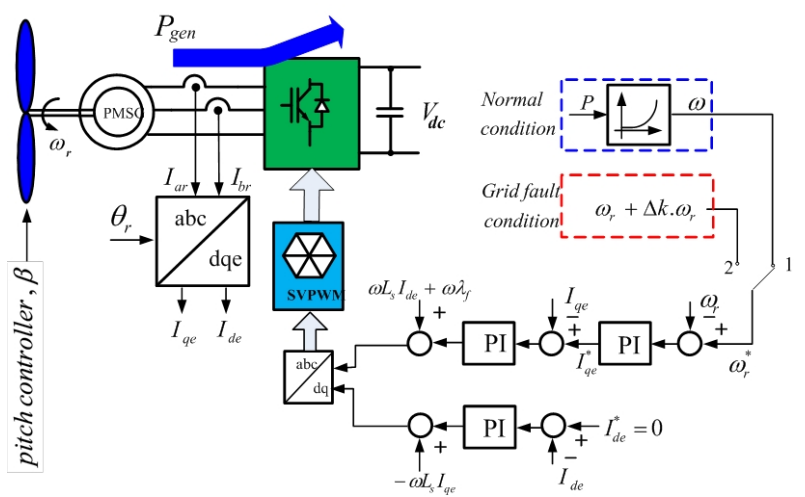

Fig. 3. Control block diagram of PMSG.

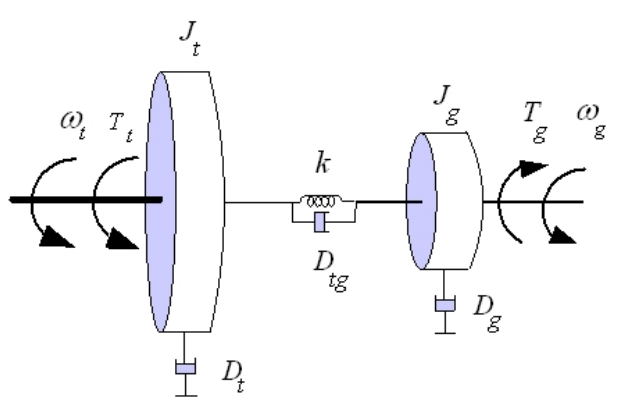

Fig. 4. Two-mass model for drive train of wind turbine.

where $T_{t}$ is the turbine torque; $J_{t}$ is the inertia of the turbine; $T_{k}$ and $T_{g}$ are the torques in the flexible coupling and the generator, respectively; $\omega_{t}$ and $\omega_{g}$ are the mechanical speed of the turbine and the generator, respectively; and $J_{g}$ is the inertia of the generator side.

Define the fault duration and the generator speed change as $\Delta T$ and $\Delta k(\%)$, respectively. From (1), (2) and the inertia constant of the system, the mechanical power, $P_{J}$, for speed variation is expressed as [14]:

$$
P_{J}=2 P_{\text {rated }}\left(H_{M}+H_{G}\right) \frac{\Delta k}{\Delta T}
$$

where, $H_{M}$ and $H_{G}$ are the inertia constants of the wind turbine and the generator, respectively, and Prated is the rated system power.

\section{ENERGy StORAGE SySteM}

\section{A. Control of the ESS}

Under voltage sags, the generator output power may exceed the maximum level which the grid can absorb through the LSC due to decreases in the grid voltage. Therefore, to keep the DC-link voltage constant, the ESS is activated to absorb the differential energy between the generator and grid, which is expressed as:

$$
P_{\text {diff }}=P_{\text {gen }}-\left.P_{\text {grid }}\right|_{\max \text { posibility }}
$$

where $P_{\text {diff }}$ is the differential power between the generator and the grid, $P_{g e n}$ is the generator power, and $P_{\text {grid }}$ is the grid power. During a voltage sag, the LSC is operated at its rated current. As a result, the generator can deliver as much power to the grid as is possible. 


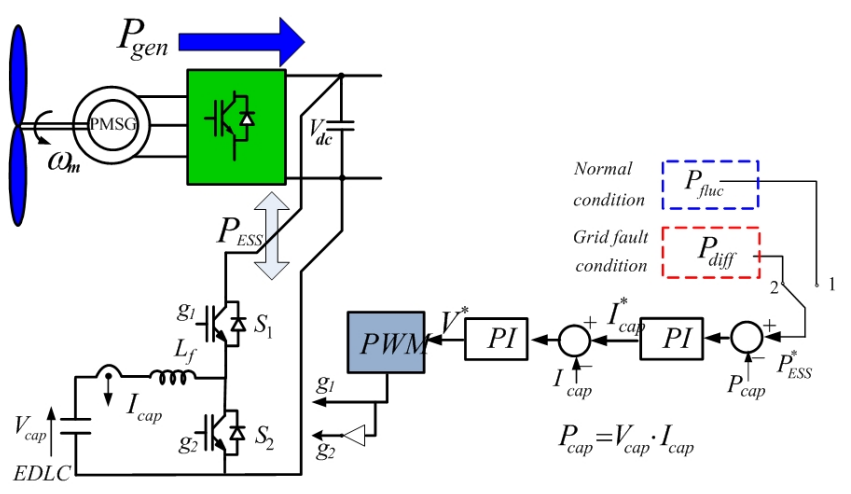

Fig. 5. Control block diagram for ESS.

On the other hand, the ESS can improve the grid power quality by charging or discharging the fluctuated power component due to wind speed variations. It is known that the power fluctuations in a particular frequency region (between 0.05 and $1 \mathrm{~Hz}$ ) result in a system frequency deviation [15]. Therefore, in order to eliminate the power fluctuations, the ESS needs to absorb or release the high frequency component of the power $P_{\text {flux }}$, which is obtained by applying a second-order high-pass filter to the generator power so that:

$$
P_{f l u c}=\frac{s^{2}}{s^{2}+2 \xi \omega_{c} s+\omega_{c}^{2}} P_{g e n}
$$

where $\xi$ is the damping ratio, and $\omega_{c}$ is the cut-off frequency $\left(\omega_{c}=2 \pi f_{c}\right)$. In this paper, the cut-off frequency is chosen to be $0.1 \mathrm{~Hz}$.

The role of the ESS is to absorb the power from the PMSG or to release it to the grid, as required. For this purpose, a power controller is used in the main control loop with an inner current control loop as shown in Fig. 5. The power reference is given by (4) for ride-through and (5) for power smoothening.

\section{B. Rating of the ESS}

In order to meet the requirements of the grid code, the ESS should have the capability to absorb the full differential energy between the generator and the grid in a worst case scenario. By increasing the generator speed during a voltage sag, the ESS can be made small in size since some turbine output power is stored in the inertia of the system. The rated power for the LVRT, $P_{L V R T}$, is determined by considering the grid code shown in Fig. 1. The stored power in the system inertia during a voltage sag expressed as:

$$
P_{L V R T}= \begin{cases}\left(0.9-V_{\min }\right) P_{\text {rated }}-P_{J} & 0 \leq t \leq t_{1} \\ \frac{\left(0.9-V_{\min }\right) P_{\text {rated }}}{t_{2}-t_{1}}\left(t_{2}-t\right) & t_{1}<t \leq t_{2} .\end{cases}
$$

The energy stored in the ESS is expressed as:

$$
\begin{aligned}
E_{L V R T} & =\int_{0}^{t_{1}}\left[\left(0.9-V_{\min }\right) P_{\text {rated }}-P_{J}\right] d t \\
& +\int_{t_{1}}^{t_{2}} \frac{\left(0.9-V_{\min }\right) P_{\text {rated }}}{t_{2}-t_{1}}\left(t_{2}-t\right) d t .
\end{aligned}
$$

During the operation of the ESS, the voltage of the EDLC varies, so that its capacitance, $\mathrm{C}$, can be determined from the following relationship as:

$$
C=\frac{2 \cdot E_{L V R T}}{\Delta V_{\text {cap }} \cdot V_{\text {cap }}^{\text {rated }}}
$$

where $V_{\text {cap }}^{\text {rated }}$ and $\Delta V_{\text {cap }}$ are the rated voltage and the voltage variation of the EDLC, respectively.

It is noted that this scheme can improve the grid power fluctuations. The main cause of power oscillations in wind turbines is the wind speed variation, which is expressed as:

$$
v(t)=V_{w 0}+\sum \Delta V_{w i} \sin \left(\omega_{i} t\right)
$$

where $V_{w 0}$ is the mean wind speed, $\Delta V_{w i}$ is the harmonic amplitude, and $\omega_{i}$ is angular frequency $(f=0.1 \sim 10 \mathrm{~Hz})$. In practice, wind speed variations are randomly varied and depend on the regional environment. It is assumed that the wind fluctuation is $30 \%$ of the mean value [9], [16]. Therefore, the power capacity of the ESS in this case is suitable for shortterm energy storage as is shown clearly in the following design example.

\section{Design example for the ESS}

The parameters of the ESS are designed for a 2[MW] PMSG wind turbine system, where the total inertia constant of the wind turbine and the generator is given as $6[\mathrm{~s}]$. According to the grid code, for a $\Delta T=300[\mathrm{~ms}]$ in the LVRT curve, the system rotational speed is controlled to within $\Delta k=1.0 \%$ during this duration [17], [18]. Thus, the mechanical power stored in system inertia is, by (3):

$$
P_{J}=2 \cdot 2[M W] \cdot 6 \cdot \frac{0.01}{0.3}=0.8[M W]
$$

Then, the rated power of the ESS is calculated from the grid code and the $P_{J}$ given above, as:

$$
P_{L V R T}=(0.9-0) \cdot 2[M W]-0.8=1.0[M W] .
$$

Then, the rated energy capacity of the EDLC is given by:

$$
E_{L V R T}=\int_{0}^{0.3} 1.0 d t+\int_{0.3}^{1.5} \frac{1.8}{1.5-0.3}(1.5-t) d t=1.38[M J] .
$$

While the EDLC is charged or discharged, the voltage of the EDLC will vary, when the voltage variation is set to $20 \%$ of the rated value. In this paper, the rated voltage of the EDLC is set to 400[V]. Therefore, the capacitance of the EDLC is determined as:

$$
C=\frac{2 \cdot 1.38[M J]}{400 \cdot 80}=86.25[F] .
$$

For power fluctuation at 0.3 p.u., with this EDLC capacity, the ESS can operate during the period $T_{f l u c}$ as:

$$
T_{\text {fluc }}=\frac{1.38[M J]}{0.6[M W]}=2.3[s] \text {. }
$$




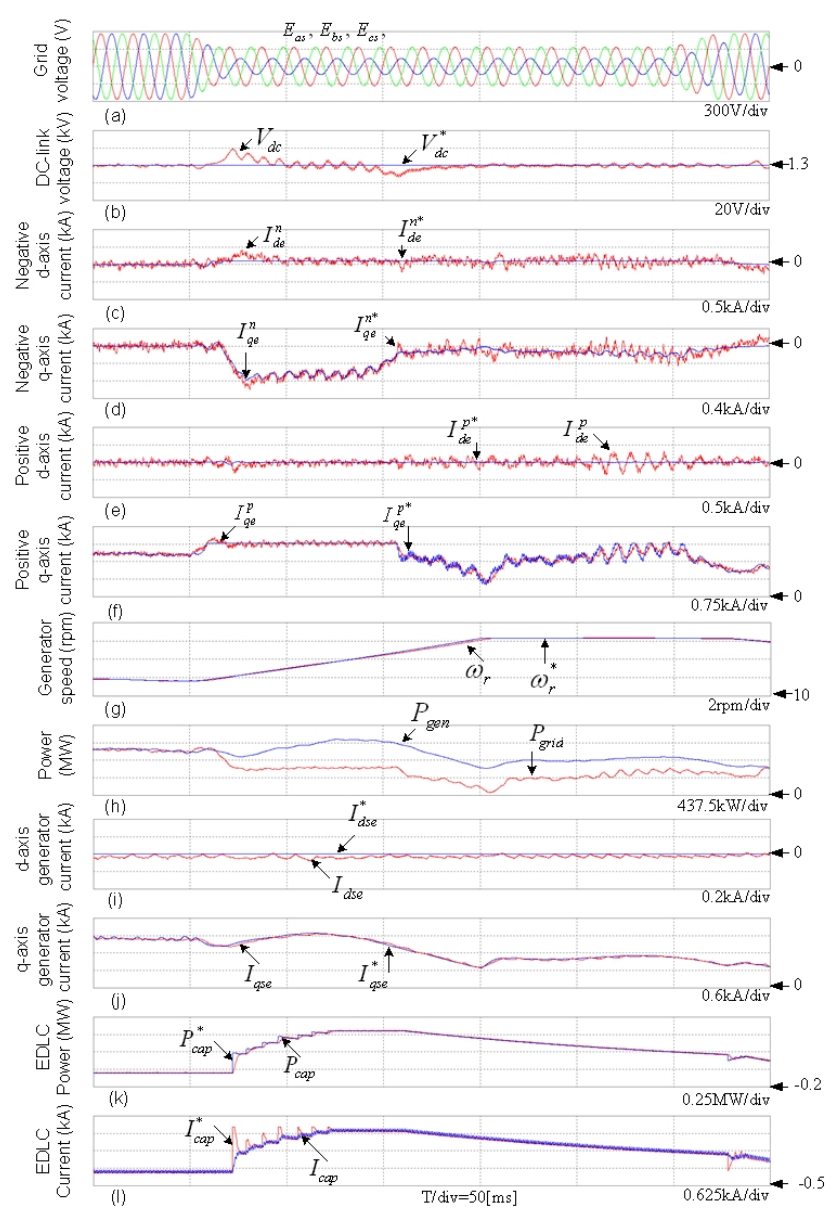

Fig. 6. System performance under unbalanced sag (a) Grid voltage, (b) DC-link voltage, (c) negative d-axis grid current, (d) negative q-axis grid current, (e) positive d-axis grid current, (f) positive q-axis grid current, (g) generator speed, (h) system power, (i) d-axis generator current, (j) q-axis generator current, (k) EDLC power, (l) EDLC current.

\section{Simulation Results}

To verify the feasibility of the proposed scheme, PSIM simulations have been performed for a 2[MW] PMSG wind turbine system. The system parameters for the simulation are listed in Table I and Table II. The grid voltage is $0.69[\mathrm{kV}] / 60[\mathrm{~Hz}]$ and it has an unbalanced sag for $250[\mathrm{~ms}]$. The parameters of the ESS are listed in Table III.

Fig. 6 shows the system performance under an unbalanced voltage sag. The DC-link voltage is controlled at its reference for an unbalanced grid voltage as shown in Fig. 6(b). The negative-sequence $\mathrm{d}$ - and q-axis current components are shown in Fig. 6(c) and (d), respectively. Fig. 6(e) and (f) show the positive-sequence d- and q-axis current components, respectively. In order to reduce the turbine power when a gird fault happens, the generator speed is increased as shown in Fig. $6(\mathrm{~g})$.

Fig. 6(h) and (k) show the relationship between the generator, the grid and the ESS power. Fig. 6(i) and (j) show the current control performance of the PMSG. The control performance of the ESS is good and the power and the current in the ESS are shown in Fig. 6(k) and (1), respectively.

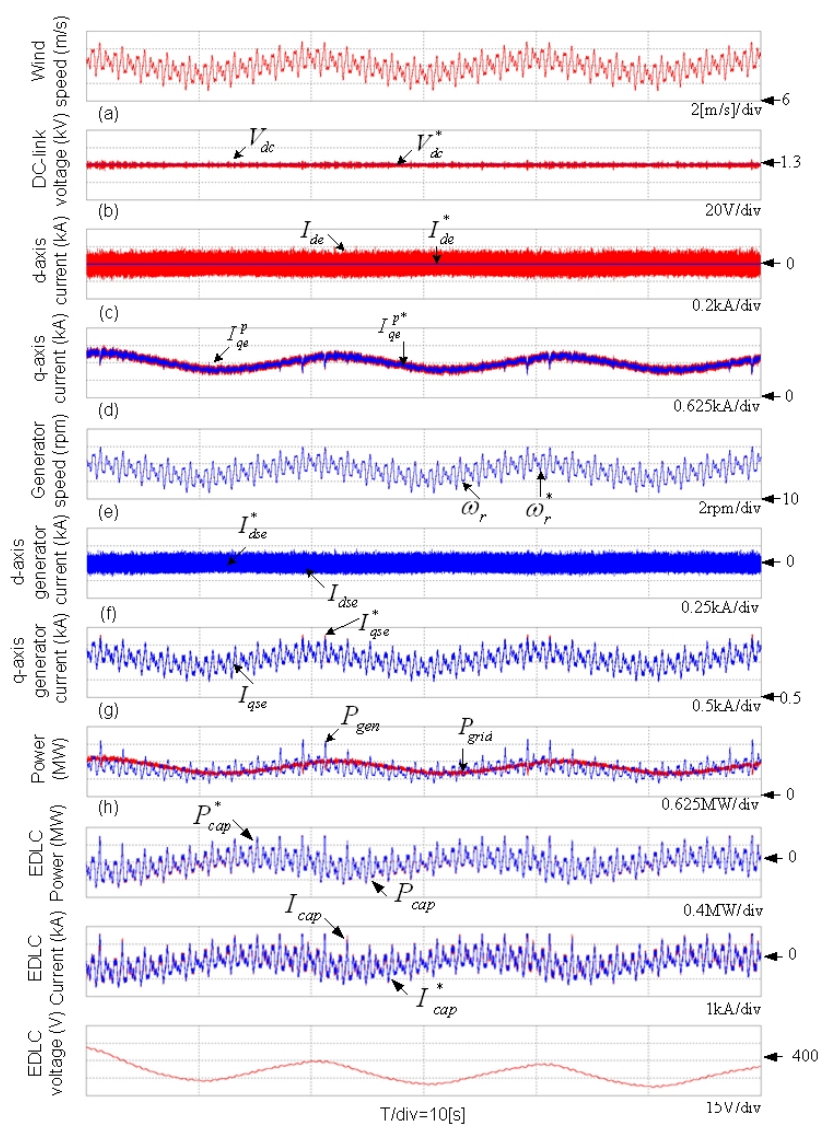

Fig. 7. System performance under wind speed variation (a) Wind speed, (b) DC-link voltage, (c d-axis grid current, (d) q-axis grid current, (e) generator speed, (f) d-axis generator current, (g) q-axis generator current, (h) system power, (i) EDLC power, (j) EDLC current, (k) EDLC voltage.

Fig. 7 shows the system performance under wind speed variations (Fig. 7(a)). Fig. 7(b), (c) and (d) show that the control performance of the LSC is good under wind variations. The control of the GSC is also good as shown in Fig. 7(e), (f) and $(\mathrm{g})$. Fig. 7(h) shows the generator and the grid power, while the generator power is oscillated due to wind speed variations. Due to the ESS and a braking chopper, the power delivered to the grid is smoothened. Fig. 7(i) shows the pulsated power of the generator absorbed from or released to the grid. The power and current controllers operate well as shown in Fig. 7(i) and (j), respectively. Fig. 7(k) shows the EDLC voltage, which is varied according to charging and discharging.

\section{EXPERIMENTAL RESULTS}

An experiment has been carried out in the laboratory to verify the validity of the proposed algorithm. The experimental setup consists of a $3 \mathrm{~kW}$-induction motor as a wind turbine simulator and a $2.68 \mathrm{~kW}-\mathrm{PMSG}$. The

parameters of the PMSG are shown in Table IV, and those of the energy storage system are listed in Table V. The grid voltage is $160[\mathrm{~V}] / 60[\mathrm{~Hz}]$. The DC-link voltage is controlled at 240[V] for the IGBT back-to-back PWM converters, for which the switching frequency is $5[\mathrm{kHz}]$. For a sag generator, a three-phase auto transformer has been used. 


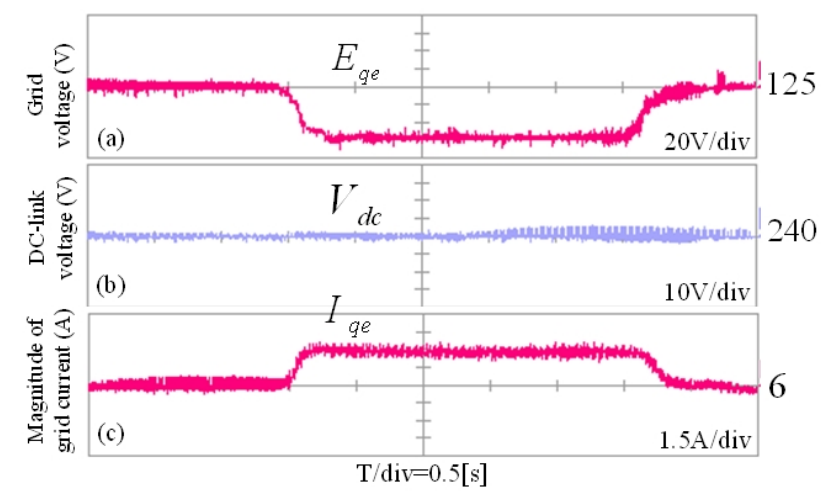

Fig. 8. (a) Grid voltage. (b) DC-link voltage. (c) grid current.

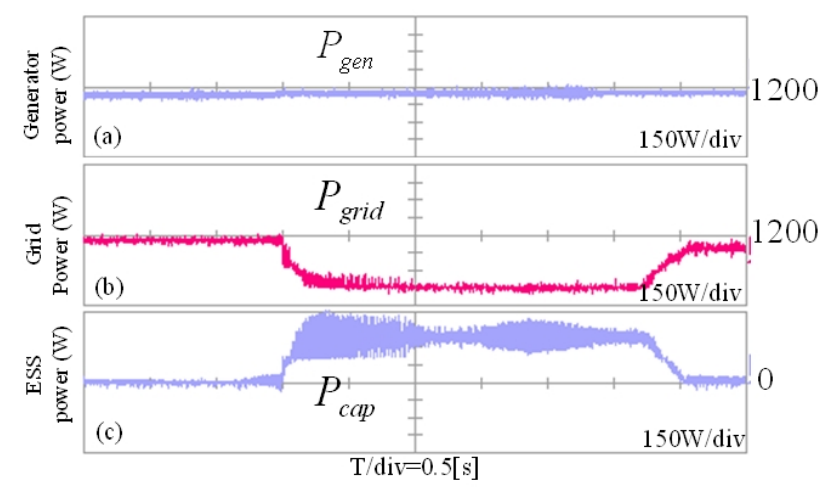

Fig. 9. System powers. (a) Generator power. (b) grid power. (c) ESS power.

For a balanced sag, the amplitude of the three-phase grid voltage is reduced at the same time, as shown in Fig. 8(a), which is about $50 \%$ of the sag. Fig. 8(b) shows the DC-link voltage which is kept constant during the voltage sag. Fig. 8(c) shows the q-axis grid current. During the voltage sag, the grid current is increased to deliver as much power to the grid as possible. Fig. 9 shows the power balance associated with the generator, the grid and the ESS. At a voltage sag, the grid power is reduced as shown in Fig. 9(b) since the grid voltage is decreased. The differential power between the generator and the grid is absorbed by the ESS as shown in Fig. 9(c).

The performance of the ESS control is shown in Fig. 10. The power reference of the ESS is given by (4). Fig. 10(a) shows that the power control performance is good. The current controller also works well as shown in Fig. 10(b).

Next, the validity of the proposed control algorithm is investigated in the case of power fluctuations due to wind speed variations. The waveforms of these fluctuations are shown in Fig. 11. The wind speed is shown in Fig. 11(a). The generator power is fluctuated as shown in Fig. 11(c). Due to the ESS, the grid power can be smoothened as shown in Fig. 11(d). Fig. 11(e) and (f) show the performance of the power and current controllers of the ESS, respectively. Fig. $11(\mathrm{~g})$ shows the capacitor voltage, which is varied according to charging and discharging.

\section{CONCLUSIONS}

This paper has proposed ride-through and power smoothening techniques for PMSG wind turbine systems using an

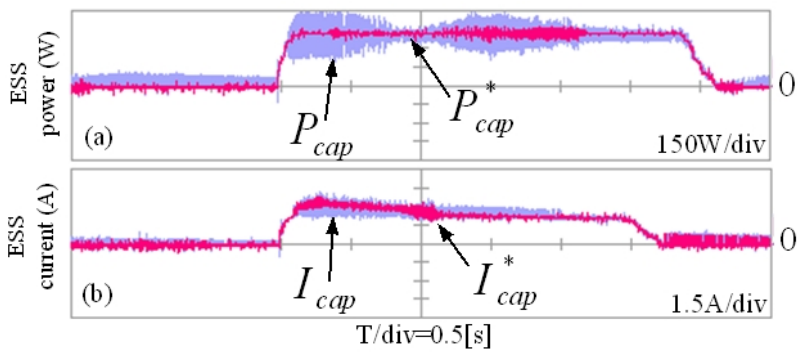

Fig. 10. Control performance of ESS. (a) Power. (b) current.

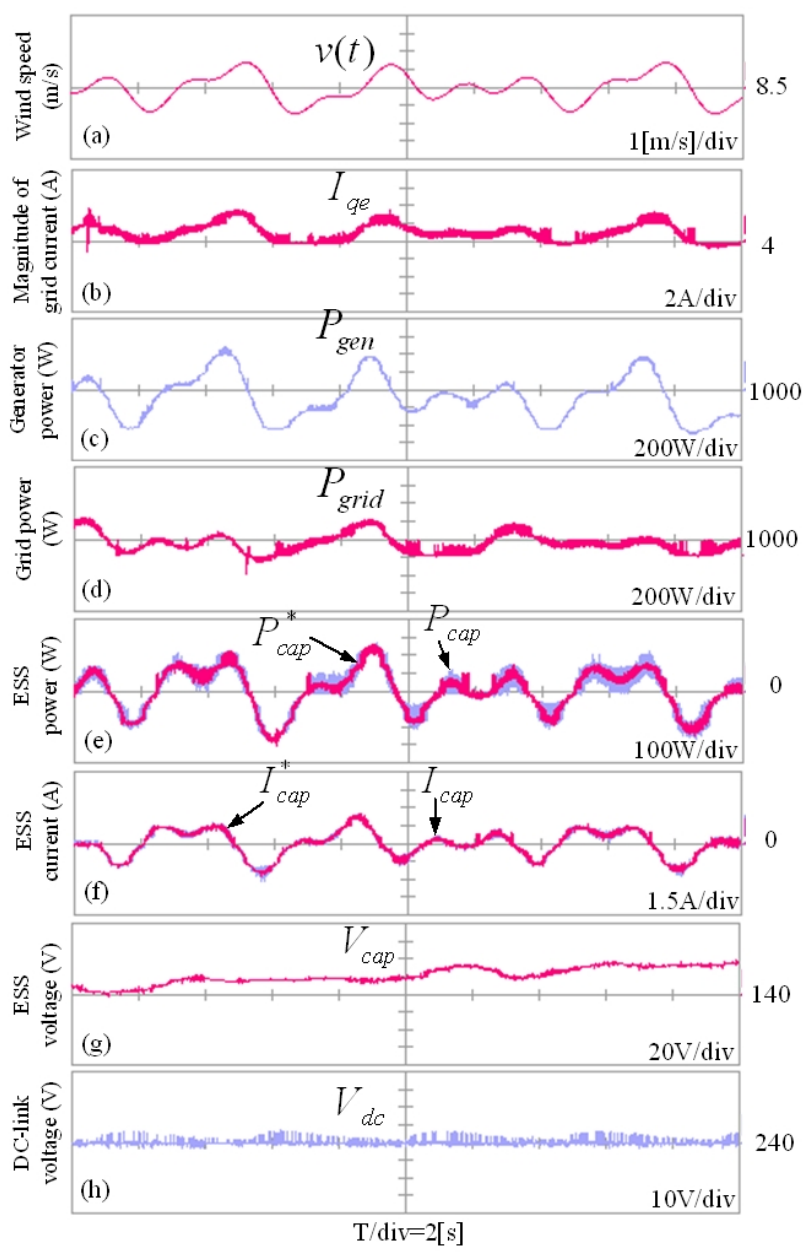

Fig. 11. Responses of system for wind speed variation

(a) Wind speed, (b) grid current, (c) generator power, (d) grid power, (e) ESS power, (f) ESS current, (g) ESS voltage, (h) DC-link voltage.

ESS. It has been shown that the power capacity of the ESS can be reduced by up to half of the power rating of the system, when compared with the conventional method, while the performance of the system is kept unchanged under power fluctuations and abnormal grid voltage conditions. Simulations and experiment results have verified the proposed method.

\section{APPENDIX}

The parameters of the generators, the wind turbine and the ESSs used for the simulations and experiments are listed in Table I - V. 
TABLE I

PARAMETERS OF 2[MW] PMSG (SIMUlation)

\begin{tabular}{|c|c|}
\hline Parameters & Values \\
\hline Rated power & $2[\mathrm{MW}]$ \\
\hline Stator voltage/frequency & $690[\mathrm{~V}] / 60[\mathrm{~Hz}]$ \\
\hline Stator resistance & $0.008556[\Omega]$ \\
\hline d-axis inductance & $0.00359[\mathrm{H}]$ \\
\hline q-axis inductance & $0.00359[\mathrm{H}]$ \\
\hline
\end{tabular}

TABLE II

PARAMETERS OF TURBine Blade (SIMUlation)

\begin{tabular}{|c|c|}
\hline Parameters & Values \\
\hline Blade radius & $39[\mathrm{~m}]$ \\
\hline Air density & $1.225\left[\mathrm{~kg} / \mathrm{m}^{3}\right]$ \\
\hline Max. power conv. coefficient & 0.40 \\
\hline Optimal tip-speed ratio & 8.0 \\
\hline Cut-in speed & $3[\mathrm{~m} / \mathrm{s}]$ \\
\hline Rated wind speed & $14.9[\mathrm{~m} / \mathrm{s}]$ \\
\hline Moment of inertia & $6.3 \times 106\left[\mathrm{~kg} \cdot \mathrm{m}^{2}\right]$ \\
\hline Gear ratio & 1 \\
\hline
\end{tabular}

TABLE III

ESS PARAMETERS FOR 2[MW] SYSTEM (SIMULATION)

\begin{tabular}{|c|c|}
\hline Parameters & Values \\
\hline Rated energy of EDLC & $2.46[\mathrm{MJ}]$ \\
\hline ESS power rating $\left(P_{\text {ESSrated }}\right)$ & $1.0[\mathrm{MW}]$ \\
\hline Capacitance of EDLC $(C)$ & $153.75[\mathrm{~F}]$ \\
\hline Operating voltage $\left(V_{\text {cap }}\right)$ & $400[\mathrm{~V}]$ \\
\hline
\end{tabular}

TABLE IV

PARAMETERS OF PM MACHINE (EXPERIMENT)

\begin{tabular}{|c|c|}
\hline Parameters & Values \\
\hline Rated power & $2.68[\mathrm{~kW}]$ \\
\hline Number of poles & 6 \\
\hline Rated current & $9.8[\mathrm{Arms}]$ \\
\hline Rated speed & $1200[\mathrm{rpm}]$ \\
\hline Torque coefficient & $1.72[\mathrm{~N} \cdot \mathrm{m} / \mathrm{A}]$ \\
\hline Inertia & $0.00331\left[\mathrm{~kg} \cdot \mathrm{m}^{2}\right]$ \\
\hline Resistance & $0.49[\Omega]$ \\
\hline Inductance & $5.35[\mathrm{mH}]$ \\
\hline
\end{tabular}

TABLE V

PARAMETERS OF ESS (EXPERIMENT)

\begin{tabular}{|c|c|}
\hline Parameters & Values \\
\hline Inductor & $3.17[\mathrm{mH}]$ \\
\hline Electrolytic capacitor & $170[\mathrm{mF}]$ \\
\hline DC operating voltage & $150[\mathrm{~V}]$ \\
\hline Switching frequency & $5[\mathrm{kHz}]$ \\
\hline
\end{tabular}

\section{ACKNOWLEDGEMENT}

This work has been supported by the Korea Electrical Engineering and Science Research Institute (08310), which is funded by Korea Western Power Co., Ltd.

\section{REFERENCES}

[1] T. Ackermann, J. R. Abbad, I. M. Dudurych, I. Erlich, H. Holttinen, J. R. Kristoffersen, and P. E. Sorensen, "European balancing act," IEEE Power and Energy Magazine, Vol. 5, No. 6, pp. 90-103, Nov./Dec. 2007.

[2] P. Sorensen, N. A. Cutuluis, A. V. Rodriguez, L. E. Jensen, J. Hjerrild, M. H. Donovan, and H. Madsen, "Power fluctuations from large wind farms," IEEE Trans. Power Syst., Vol. 22, No. 3, pp. 958-065, Aug. 2007.

[3] W. Li, G. Joos, and C. Abbey, "Wind power impact on system frequency deviation and an ESS based power filtering algorithm solution," in Proc. of IEEE PESC, pp. 2077-2084, Nov. 2006.
[4] J. F. Conroy and R. Watson, "Low-voltage ride-through of a full converter wind turbine with permanent magnet generator," IET Renew. Power. Gener., Vol. 1, No. 3, pp. 182-189, Sep. 2007.

[5] W. Li, C. Abbey, and G. Joos, "Control and performance of wind turbine generators based on permanent magnet synchronous machines feeding a diode rectifier," in Proc. of IEEE PESC, pp. 1-6, Jun. 2006.

[6] N. Heng, L. Jiao, Z. Peng, and H. Yikang, "Improved control strategy of an active crowbar for directly-driven PM wind generation system under grid voltage dips," in Proc. of IEEE ICEMS, pp. 2294-2298, Oct. 2008.

[7] C. Abbey and G. Joos, "Supercapacitor energy storage for wind energy applicatons," IEEE Trans. Ind. App., Vol. 43, No. 3, pp. 769-776, May/Jun. 2007.

[8] N. P. W. Strachan and D. Jovcic, "Improving wind power quality using an integrated wind energy conversion and storage system (WECSS)," Power and Energy Society General Meeting, IEEE, pp. 1-6, Jul. 2008,

[9] W. Li and G. Joos, "Performance comparison of aggregated and distributed energy storage systems in a wind farm for wind power fluctuation suppression," in the Proc. of IEEE PES, pp. 1-6, Jun. 2007.

[10] S. M. Muyeen, R. Takahashi, T. Murata, and J. Tamura, "Integration of an energy capacitor system with a variable-speed wind generator," IEEE Trans. Energy Convers., Vol. 24, No. 3, pp. 740-749, Sep. 2009.

[11] R. Data and V. T. Ranganathan, "A method of tracking the peak power points for a variable speed wind energy conversion system," IEEE Trans. Energy Convers., Vol. 18, No. 1, pp. 163-168, Mar. 2003.

[12] J.-I. Jang and D.-C. Lee, "High performance control of three-phase PWM converters under nonideal source voltage," in Proc. of IEEE ICIT, pp. 2791-2796, Dec. 2006.

[13] H- S. Song and K. Nam, "Dual current control scheme for PWM converter under unblanced input voltage conditions", IEEE Trans. Ind. App., Vol. 46, No. 5, pp. 953-959, Oct. 1999.

[14] V. Akhmatov, Induction Generators for Wind Power, Multi-Science Publishing Company, Chap. 3, 2005.

[15] C. Luo, H. Banakar, B. Shen, and B. T. Ooi, "Strategy to smooth wind power fluctuation of wind turbine generator," IEEE Trans. Energy Convers., Vol. 22, No. 2, pp. 341-349, Jun. 2007.

[16] S. M. Muyeen, R. Takahashi, T. Murata, and J. Tamura, "A new control method of energy capacitor system in DC-based wind farm," in Proc. of IEEE ECCE, pp. 1619-1625, Sep. 2009.

[17] J. Morren, J. Pierik, and S. W. H. de Haan, "Inertial response of variable speed wind turbines," Electric Power Systems Research, Vol. 76, No. 11, pp 980-987, Jul. 2006.

[18] D. Xiang, L. Ran, P. J. Tavner, and S. Yang, "Control of a doubly fed induction generator in a wind turbine during grid fault ride-through," IEEE Trans. Energy Convers., Vol. 21, No. 3, pp. 652-662, Sep. 2006.

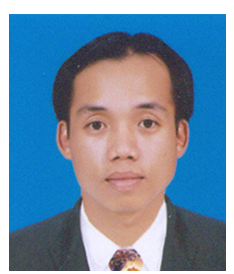

Thanh Hai Nguyen was born in Dong Thap, Viet Nam in 1980. He received his B.S. in Engineering from the Technology University of Ho Chi Minh city, in 2003 and his M.S. in the Department of Electrical Engineering, Yeungnam University, Korea in 2010 where, he is currently working toward his Ph.D. He was an Assistant Lecturer in the College of Technology, Can Tho University, Viet Nam in 2003. His research interests include power converters, machine drives, and wind

power generation.

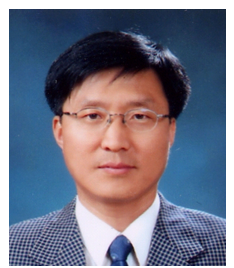

Dong-Choon Lee received his B.S., M.S., and Ph.D. in Electrical Engineering from Seoul National University, Seoul, Korea, in 1985, 1987, and 1993, respectively. He was a Research Engineer with Daewoo Heavy Industry from 1987 to 1988 . Since 1994, he has been a Faculty Member in the Deptartment of Electrical Engineering, Yeungnam University, Gyeongbuk, Korea. As a Visiting Scholar, he joined the Power Quality Laboratory, Texas A\&M University, College Station in 1998, and the Electrical Drive Center, University of Nottingham, U.K. in 2001, and the Wisconsin Electric Machines and Power Electronic Consortium, University of Wisconsin, Madison in 2004. His research interests include ac machine drives, control of power converters, wind power generation, and power quality. 